\title{
Morphology and Structural Properties of Undoped and Cobalt Doped Magnetic Iron Oxide Particles for Improving the Environmental Quality
}

\author{
Erwin Amiruddin, Amir Awaluddin, Meilan Sihombing, Azura Royka, Tissa Syahrul
}

\begin{abstract}
Doping of metal ions in magnetic iron oxide particles can improve its performance and lead to its new technological and industrial applications. Magnetic iron oxide particles of undoped and cobalt doped were synthesized from natural sand of Logas District Kuansing Regency by ball milling method. The structural properties and the morphology of the magnetic iron oxide $\mathrm{Fe}_{2} \mathrm{O}_{3}$ particles were analyzed using $X$-Ray Diffractometer (XRD) and scanning electron microscope (SEM). The $X$-ray diffractometric study showed that $X$-ray diffraction (XRD) peaks shift to slightly higher angles as compared to those of undoped magnetic iron oxide particles. This shift is due to relatively smaller ionic radius of cobalt as compared to those for iron. Moreover, peaks corresponding to cobalt oxide or metal cobalt could not be observed in the diffraction pattern. Some other diffraction peaks from other crystalline forms such as silicon (Si) and titanium (Ti) were observed.
\end{abstract}

Keywords: iron oxide particles, cobalt doped, morphology, structural properties and ball milling.

\section{INTRODUCTION}

Magnetic iron oxide nanoparticles have been the subject of today research since this particle can be obtained from rock and soils. Magnetic iron oxides exist in nature in many forms, however, the most common forms are hematite $\left(\alpha-\mathrm{Fe}_{2} \mathrm{O}_{3}\right)$, maghemite $\left(\gamma-\mathrm{Fe}_{2} \mathrm{O}_{3}\right)$ and magnetite $\left(\mathrm{Fe}_{3} \mathrm{O}_{4}\right)^{[1]}$. In a nanometer scale, magnetic iron oxide particles has a unique property namely superparamegnetic. Moreover, the high surface area to volume ratio posses by magnetic iron oxide nanoparticles results excellent properties such as enhanced catalytic activity ${ }^{[2,3]}$. Since magnetic iron oxide nanoparticles can be control by external magnetic field, then its application become broader such as environmental material ${ }^{[4,5]}$, magnetic data storage ${ }^{[6]}$, magnetic sensor ${ }^{[7]}$, inks for photocopy machines ${ }^{[8]}$ magnetic resonance imaging ${ }^{[9-10]}$, and drug delivery target ${ }^{[11,12]}$. It is also commonly known that the

Revised Manuscript Received on July 10, 2020.

* Correspondence Author

Erwin Amiruddin*, Department of Physics, Faculty of Mathematics and Natural Sciences, Riau University, Indonesia.

Amir Awaluddin, Department of Chemistry, Faculty of Mathematics and Natural Sciences, Riau University, Indonesia.

Meilan Sihombing, Magnetic Laboratory, Department of Physics, Faculty of Mathematics and Natural Sciences, Riau University, Indonesia.

Azura Royka, Magnetic Laboratory, Department of Physics, Faculty of Mathematics and Natural Sciences, Riau University, Indonesia.

Tissa Syahrul, Magnetic Laboratory, Department of Physics, Faculty of Mathematics and Natural Sciences, Riau University, Indonesia.

(c) The Authors. Published by Blue Eyes Intelligence Engineering and Sciences Publication (BEIESP). This is an open access article under the CC BY-NC-ND license (http://creativecommons.org/licenses/by-nc-nd/4.0/) magnetic particles can remove the pollutant in contaminated water based on magnetic extraction technique. ${ }^{[3]}$

It is well known that magnetic iron oxide nanoparticles can be synthesized using many methods hydrothermal reaction $^{[14-16]}$, microwave ${ }^{[17]}$, sol-gel method ${ }^{[18,19]}$, micro emulsion method ${ }^{[20]}$, forced hydrolysis ${ }^{[21]}$ and physical methods $^{[22,24]}$. In physical methods, one of well-known methods is ball milling ${ }^{[25-27]}$.This method is simple, efficient, high yield and low cost compared to other methods. Previous researchers ${ }^{[28-31]}$ have used ball milling method to produce magnetic iron oxide nanoparticles. For example, In order to produce iron oxide particles $\left(\mathrm{Fe}_{2} \mathrm{O}_{3}\right)$, the researcher ${ }^{[28]}$ used ball milling method. Moreover, other researchers. ${ }^{[31]}$ used high-energy ball milling to prepare $10 \mathrm{~nm} \alpha-\mathrm{Fe}_{2} \mathrm{O}_{3}$ nanoparticles directly from crude $\alpha-\mathrm{Fe}_{2} \mathrm{O}_{3}$ by, and found that the surface anisotropy constant of $\alpha-\mathrm{Fe}_{2} \mathrm{O}_{3}$ nanoparticles is higher than bulk material produced by this method. Moreover, magnetic properties, phase and morphology of the obtained particles are depended on time, speed and types of milled balls. One of the most important parameters for controlling the magnetic properties of magnetic iron oxide nanoparticles is the size of the particles. However, development of a simple, reliable, and low cost methodology to synthesize magnetic iron oxide nanoparticles with controllable size and size distribution remains a challenging task for researchers. According to previous researchers ${ }^{[32]}$, when transition metal elements doped into nanoparticles, they will alter the structural properties of that nanoparticles. Moreover, doping methodology and selection of doped transition ions influence the properties of magnetic iron oxide nanoparticles. In this paper, we have investigated the morphology and structural properties of undoped and cobalt doped magnetic iron oxide particles of natural sand from Logas, Kuansing District, Riau Province using ball-milling method.

\section{EXPERIMENTAL METHOD}

Natural sand samples were collected from Logas, Kuansing Regency, and Riau Province. Prior to ball milling process, then magnetic and non-magnetic particles of the sample were separated using iron sand separator. The product of iron sand separator was milled using ball milling for 90 hours. The magnetic and nonmagnetic particles were separated again using neodymium iron boron magnet (NdFeB). The magnetic particles were milled for another for 30 hours.

\section{Published By:}

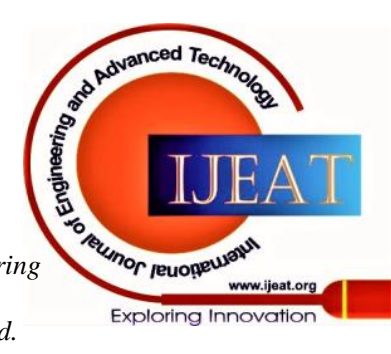


Finally, the product of last milling was milled together with cobalt nitrate $\mathrm{Co}\left(\mathrm{NO}_{3}\right)_{2} \cdot 4 \mathrm{H}_{2} \mathrm{O}$ as a dopant for 20 hours in order to obtain a fine powder. The elemental identification of the samples before and after milling was obtained using $\mathrm{X}$ Ray Fluorescence Spectrometer (XRF). The morphology and particles size of selected samples were determined using scanning electron microscope (SEM). Structural and magnetic phases of synthesized samples before and after cobalt doped magnetic iron oxide particles were studied using $\mathrm{X}$-Ray Diffractometer (XRD) technique equipped with $\mathrm{Cu} \mathrm{K}_{\alpha}$ radiation of $\lambda=0.15406 \mathrm{~nm}$.

\section{RESULTS AND DISCUSSION}

Elemental composition of natural sand before and after ball milling process was determined using X-ray fluorescence spectroscopy (XRF). This composition is presented in Fig. 1 below.

Figure 1. Elemental composition of natural sand from Logas Village, Kuansing District Riau Province observed by XRF.

Fig. 1 shows that the elemental composition of natural sand from Logas Village, Kuansing District Riau Province was affected by milling processing time. It shows that the Fe contents were increased very significantly after two-step milling (90 + 30 hours). Some other elements for examples Si , $\mathrm{Al}, \mathrm{K}$, and $\mathrm{Ca}$ were decreased, however, the other elements such as Ti was increased. This indicates that natural sand grains break into smaller parts so that the non-magnetic and magnetic grains were separated during milling process. Moreover, it is clear that $\mathrm{Fe}$ and $\mathrm{Ti}$ elements cannot be separated until 120 hours milling process suggesting that $\mathrm{Fe}$ and $\mathrm{Ti}$ were highly agglomerated particles in the form of compound of $\mathrm{FeTiO}_{3}$ as indicates in X-ray diffraction patterns and X-ray fluorescence spectroscopy (XRF).

\section{X-Ray Diffraction Studies}

Magnetic phases for undoped and cobalt doped magnetic iron oxide particles were obtained using X-Ray Diffractometer Phillips that produced $\mathrm{x}$-ray radiation with wavelength of $0.15406 \mathrm{~nm}$. In this measurement, the diffraction angle was selected in interval of $10^{\circ}$ to $100^{\circ}$ with the step of $0.01^{\circ}$. $\mathrm{X}$-ray diffraction patterns were obtained by applying high voltage source that is around $40 \mathrm{kV}$ and $30 \mathrm{~mA}$. X- ray diffraction patterns of an undoped and cobalt doped magnetic iron oxide particles are shown in Fig. 2a and 2b respectively. It can be easily found that the diffraction peaks on undoped magnetic iron oxide particles at $2 \theta$ value of $23.8974^{\circ}$, $26.6191^{\circ}, 32.7441^{\circ}, 35.3607^{\circ}, 40.4771^{\circ}, 48.6979^{\circ}$, and

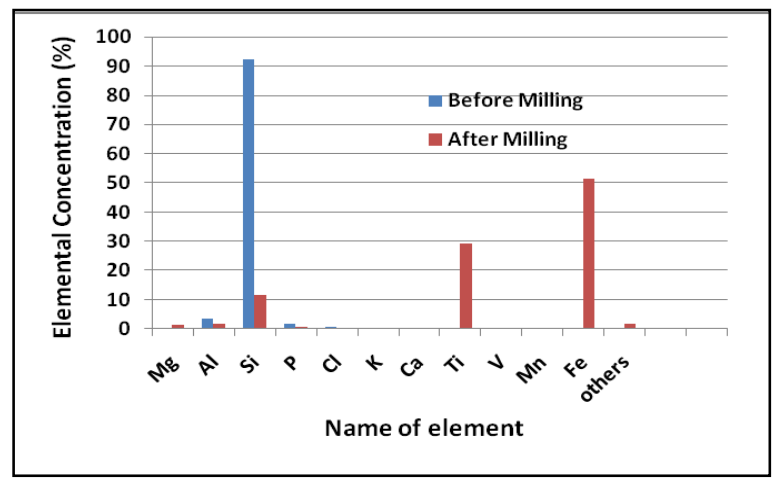

$53.4299^{\circ}$ are completely matched the reflections of (012), (211), (104), (110), (113), (024), and (116) respectively

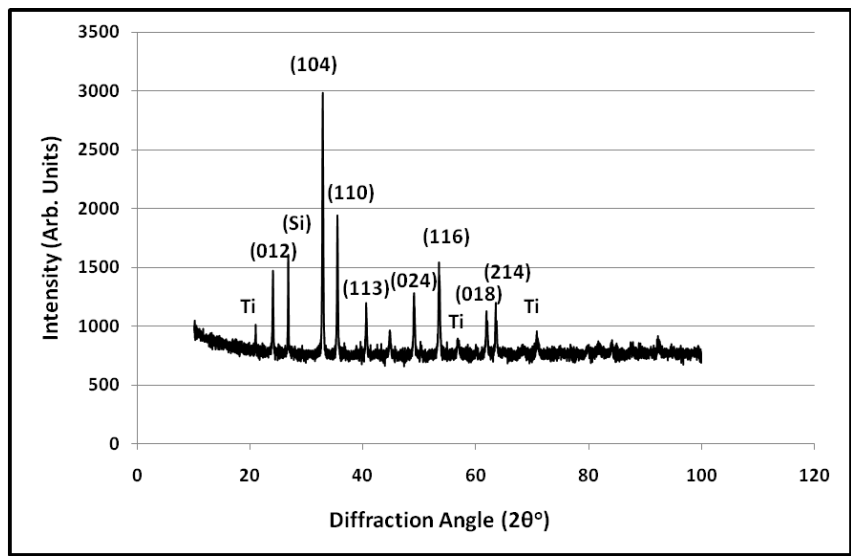

(a)

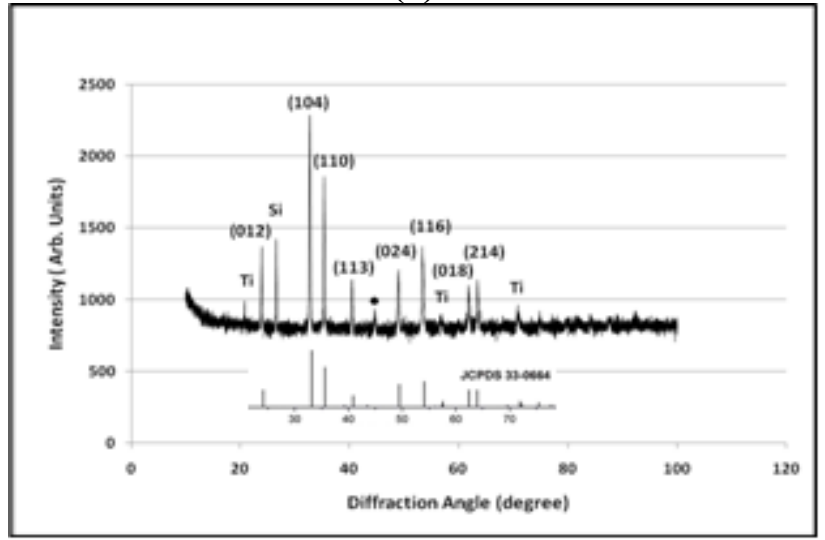

(b)

Figure 2. X-ray diffraction patterns for (a) undoped magnetic iron oxide particles and (b) cobalt doped magnetic iron oxide particles. The inset pattern shows the standard peaks of $\mathrm{Fe}_{2} \mathrm{O}_{3}$ crystal structure ${ }^{[33]}$

indicates the magnetic iron oxide particles are in good agreement with the diffractions peaks of the $\mathrm{Fe}_{2} \mathrm{O}_{3}$ (JCPDS no. 33-0664) ${ }^{[33]}$. The observed diffraction peaks are narrow and sharp showed that the particles are crystallized. It can be seen from Fig. 2b that shift occurs in most peak positions to slightly higher angles are observed for cobalt doped magnetic iron oxide particles $\left(\mathrm{Fe}_{2} \mathrm{O}_{3}\right)$. This shift of peak positions to slightly higher angles such as $32.7507^{\circ}, 35.3663^{\circ}, 40.4801^{\circ}$, and $48.9844^{\circ}$ is due to smaller ionic size of cobalt as compared with that of iron. These peak positions are correspond to inter planar distances of $2.7345 \AA$, $2.3580 \AA$, $2.2284 \AA$ and $1.8596 \AA$ respectively. This finding is agree well as reported by previous researchers ${ }^{[34]}$. Therefore, small radii of cobalt ion leads to decrease in inter planar spacing unit cell of crystal structure result small shifts the peak positions to higher angles after being doped with cobalt ions. Moreover, peaks corresponding to cobalt oxide or metal cobalt could not be observed in diffraction pattern of XRD suggesting both $\mathrm{Co}$ and Fe have almost similar ionic size. It also can be seen from Fig. 2 that some other diffraction peaks from other crystalline forms such as silicon (Si) and titanium (Ti) were detected, which demonstrates that these magnetic iron oxide particles

Published By:

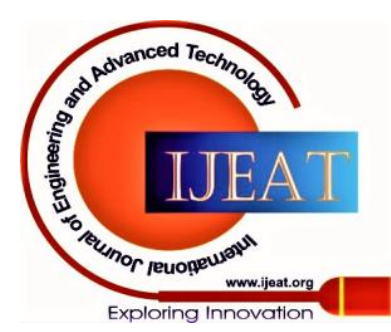


$\left(\alpha-\mathrm{Fe}_{2} \mathrm{O}_{3}\right)$ samples are not purely hematite as confirmed by $\mathrm{X}$-Ray Fluorescence Spectroscopy(XRF) results.

\section{Morphology of magnetic iron oxide particles}

The scanning electron microscopy (SEM) images of 90 hours, undoped and cobalt doped magnetic iron oxide particles for $90+30$ hours milled samples with 1000-x magnification are shown in Fig. 3.
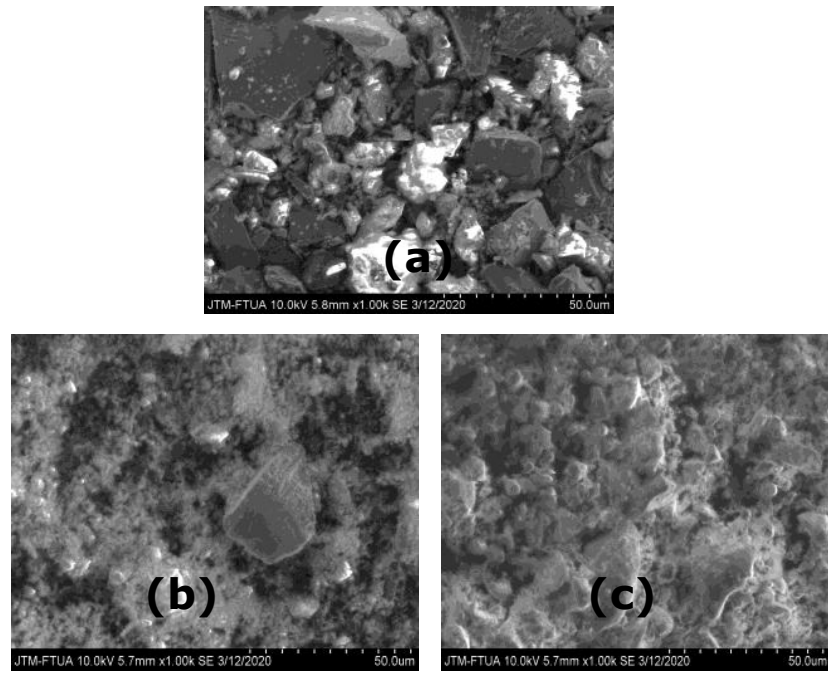

Figure 3 Scanning electron microscope images for magnetic iron oxide particles milled for (a) 90 hours (b) 90+30 hours milling and (c) 90+30 hours milling cobalt doped

In the first step of milling, after 90 hours milling time, the natural sand from Logas undergo fragmentation due to momentum transfer among milling balls and natural sand as shown in Fig. 3(a). Particles size of a synthesized magnetic iron oxide with a milling time of 90 hours was roughly estimated in the range from 20 to $200 \mu \mathrm{m}$ with irregular form. It can be noticed that particle size distribution is larger. The particles size for as synthesized magnetic iron oxide particles for milling time of $90+30$ hour is in the range from 0.5 to 50 $\mu \mathrm{m}$. Moreover, the particles size distribution is relatively narrower compared to that for 90 hours milling time as indicates in Fig. 3(a). From Fig. 3(a) and (b) it can be estimated that the average particles size decreases with increasing ball milling time. Magnetic iron oxide particles synthesised for $90+30$ hours doped with cobalt ions for 20 hours milling shows decrease in particles size. The morphology of the particles changes to particle agglomeration $^{[36]}$.

\section{CONCLUSION}

From all the findings in this work, it can be concluded that undoped and cobalt-doped magnetic iron oxide particles( $\alpha$ $-\mathrm{Fe}_{2} \mathrm{O}_{3}$ ) have been prepared using ball milling method. XRD results indicated the formation of hematite phase in both undoped and cobalt doped magnetic iron oxide particles. XRD peaks corresponding to cobalt oxide or metal cobalt could not be observed in diffraction pattern suggesting cobalt ions were both $\mathrm{Co}$ and Fe have almost similar ionic size. Some other diffraction peaks from other crystalline forms such as silicon $(\mathrm{Si})$ and ilminate $\left(\mathrm{FeTiO}_{3}\right)$ were clearly observed, which suggest that these magnetic iron oxide particles samples are not purely hematite $\left(\alpha-\mathrm{Fe}_{2} \mathrm{O}_{3}\right)$. The SEM image shows that the magnetic iron oxide particles consists of irregular shapes and different sizes and the average particles size decreases with increasing milling time.

\section{ACKNOWLEDGMENT}

The authors are grateful to Department of Physics and Chemistry Padang State University and Andalas University for providing XRD and XRF measurements and SEM images of this research work.

\section{REFERENCES}

1. R .M. Cornell and U. Schwertmann, The Iron Oxides: Structure, Properties, Reactions, Occurrences and Uses, $2^{\text {nd }}$ Edition Wiley-VCH, Weinheim, 2003.

2. P. Sharma, R. Kumar, S. Chauhan, Dilbag Singh, and M. S. Chauhan, J Nanosci Nanotechnol.2014;14:6153-6157.

3. A. Awaluddin., M. Agustina, R. Aulia, R. \& Muhdarina, Precursor effects on the morphology and crystallinity of manganese oxides and their catalytic application for methylene blue degradation. AIP Conf. Proc. 1823, 2017.

4. M. Hua, S.Zhang, B.Pan,W.Zhang, L.Lv, and Q.Zhang, Heavy metal removal from water/wastewater by nanosized metal oxides, Journal of Hazardous Materials 211-212, 2012, pp. 317- 331

5. A. Erwin, S. Salomo, P. Adhy, N. Utari, W. Ayu, Y. Wita and S. Nani, 2020, Magnetic iron oxide particles (Fe3O4) fabricated by ball milling for improving the environmental quality, IOP Conf. Series: Materials Science and Engineering 845, 012051 doi:10.1088/1757-899X/845/1/012051

6. C.T. Black, C.B. Murray, R.L. Sandstrom, S. Sun, , Science 290, 2000, 1131 .

7. ]H. Zeng, J. Li, J.P. Liu, Z.L. Wang, S.H. Sun, Nature 420, 2002, pp395.

8. M. Ataeefard, E. Ghasemi, and M. Ebadi, "Effect of micro and nanomagnetite on printing toner properties, "The Scientific World Journal, vol. , 2014, Article ID706367.

9. Zhang, S., Qi, Y.Y., Yang, H., Gong, M.F., Zhang, D. and Zou, L.G. Optimization of the Composition of Bimetallic Core/Shell $\mathrm{Fe}_{2} \mathrm{O}_{3} / \mathrm{Au}$ Nanoparticles for MRI/CT Dual-Mode Imaging.Journal of Nanoparticle Research, 15, 2013, pp2023.

10. L.X. Tifenauer, A. Tschirky, G. Kuhne, R.Y. Andres, Magn. Reson. Imaging 14, 1996, pp391.

11. Mahmoudi, M., Sant, S., Wang, B., Laurent, S., Sen, T., Advanced Drug Delivery Reviews, vol. 63, 2011, p. 24

12. Wu W, Taekyung ZW, Jiang C., Recent progression magnetic iron oxide nanoparticles: synthesis, surface functional strategies and biomedical applications. Sci.Technol. Adv. Mater.;16(023501): 2015, pp1-43

13. O'Handley R.C. Modern magnetic Materiasl. Principles and Applications, John Wiley and Sons, New York, 2000.

14. X. Wang, X. Chen, X.C. Ma, H.G. Zheng, Chem. Phys. Lett. 384, 2004, pp 391

15. Chen, F.; Gao, Q.; Hong, G.; Ni, J. Synthesis and characterization of magnetite dodecahedron nanostructure by hydrothermal method. J. Magn. Magn. Mater. 2008, 320, pp1775-1780.

16. M.Z. Wu, Y. Xing, Y.S. Jia, H.L. Niu, N.P. Qi, J. Ye, Q.W. Chen, Chem. Phys. Lett. 401 2005, pp 374.

17. Y.Z. Tang, W.M. Zhang, Chem. Res. Appl. 10, 1998, pp 419

18. A Awaluddin, E Amiruddin, R Anggraini, N Indriyani and SS Siregar, Precursor effect on the Fe-doped cryptomelane (Fe-OMS-2) prepared via one-step sol-gel route as heterogeneous Fenton catalyst for degradation of methylene blue. IOP Conf. Series: Materials Science and Engineering 845(2020) 012014 IOP Publishing doi:10.1088/1757-899X/845/1/012014

19. Itoh, H.; Sugimoto, T.J. Systematic control of size, shape, structure, and magnetic properties of uniform magnetite and maghemite particles. J. Colloid Interface Sci. 2003, 265, pp283-295.

20. K. Woo, H.J. Lee, J. Magn. Magn. Mater. 2004, pp272-276

21. J.S. Jiang, X.L. Yang, L.W. Chen, N.F. Zhou, Appl. Phys. A 45 1988, pp 245.

Published By:

Blue Eyes Intelligence Engineering

\& Sciences Publication 
22. Arbain, R., Othman, M., Palaniandy, S.: Minerals Engineering, vol. 24, 2011, pp. 1

23. E. Amiruddin and A. Prayitno, MATEC Web of Conferences 276, 06014, 2019, https://doi.org/10.1051/matecconf /201927600

24. Roy, D., Deb, P., Basumallick, A., Basu, B.: J Opt, vol. 39, 2010, no.2, pp. 102

25. N. Randrianantoandro, A.M. Mercier, M. Hervieu, J.M. Greneche, Mater. Lett. 47, 2001, pp150

26. Wang, L.-L., Jiang, J.-S., Preparation ofa- $\mathrm{Fe}_{2} \mathrm{O}_{3}$ nanoparticles by high-energy ball milling. Physica B 390, 2007, pp23-27

27. Y. Uehara, Bull. Chem. Soc. Jpn. 48 (II), 1975. pp 3383.

28. R.M. Torres Sanchez, J. Mater. Sci. Lett. 15 1996, pp 461.

29. J.S. Lee, C.S. Lee, S.T. Oh, J.G. Kim, Scr. Mater. 44, 2001, pp 2023.

30. J.S. Jiang, L. Gao, X.L. Yang, J.K. Guo, Acta Phys. Chim. Sinica 16, 2000, pp312.

31. S. Razavi-Tousi and J. Szpunar, "Effect of ball size on steady state of aluminium powder and efficiency of impacts during milling,"Powder Technology,vol.284, 2015, pp.149-158,

32. M. Ziese and M. J. Thornton, Spin Electronics. New York, NY, USA: Springer-Verlag, 2000

33. Wei Wu, Rui Hao, Fei Liu, Xintai Su and Yanglong Hou, J. Mater. Chem. A, 2013,1,6888.

34. Aseya Akbar, Saira Riaz, Robina Ashraf, and Shahzad Naseem, IEEE Transactions on Magnetics, vol. 50, No. 8, August 2014

\section{AUTHORS PROFILE}

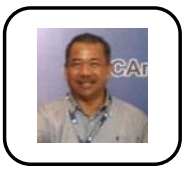

Erwin Amiruddin was born in Kerinci - Jambi 10 August 1962. He graduated from department of Physics Faculty of Mathematics and Natural Sciences Riau University in 1986 and obtained his M.Sc degree from Ball State University, Indiana USA in 1994. He completed his $\mathrm{PhD}$ in materials science from Salford University, England in 2004. He is currently working as a lecturer at the Department of Physics, Faculty of Mathematics and Natural Sciences Riau University, Indonesia. He has published more than 14 papers in journals and conference proceedings. He has also published 2 books in Physics

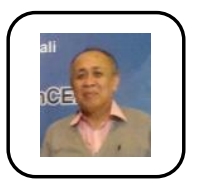

Amir Awaluddin was born in Kijang-Kepri 17 December 1962. He graduate from department of Chemistry Faculty of Mathematics and Natural Sciences Gajah Mada University (UGM) in 1988. Then he obtained a Master of Science in Chemistry degree from the University of Connecticut, USA in 1994. Later in 2004 he obtained a PhD in Chemistry from Department of Chemistry Institute of Science, Salford University. He joined the Department of Chemistry Faculty of Mathematics and Natural Sciences Riau University as a lecturer in 1988. He has published more than 27 papers in journals and conference proceedings. He has also published 3

books in Chemistry.

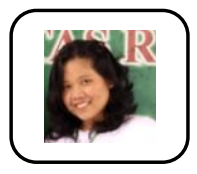

Meilan Sihombing was born in Pekanbaru 14 May 1998. She is currently a physics student Faculty of Mathematics and Natural Sciences Riau University. Now, She is working in Laboratory of Magnetic Material of the same Faculty for her final project

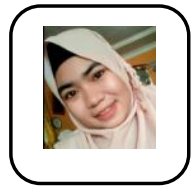

Azura Royka was born 7 June 1998 in Bangko Kanan Rokan Hilir Riau Province. She is currently a physics student Faculty of Mathematics and Natural Sciences Riau University. Now, She is working in Laboratory of Magnetic Material of the same Faculty for her final project.

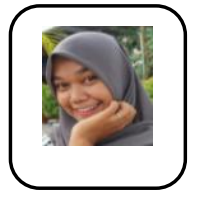

Tissa Syahrul was born 27 June 1998in Payakumbuh West Sumatera Province. She is currently a physics student Faculty of Mathematics and Natural Sciences Riau University. Now, She is working in Laboratory of Magnetic Material of the same Faculty for her final project

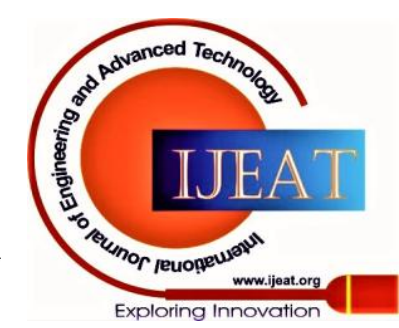

